\title{
Origin and formation of carbonaceous material veins in the 2008 Wenchuan earthquake fault zone
}

\author{
Jiang Liu', Haibing Li ${ }^{2 *}$, Jinjiang Zhang ${ }^{3}$ and Bo Zhang ${ }^{3}$
}

\begin{abstract}
This paper establishes a reference data set of carbonaceous materials (CMs) from the active fault zone of the Longmen Shan fault belt that ruptured in the 2008 Mw7.9 Wenchuan earthquake and presents an application of these data for studies of both other exhumed carbonaceous-rich fault zones and deep-drilling cores. The CMs distributed in the active fault zone are found as narrow veins and located along the slip surfaces. Microstructural observation shows that the carbonaceous material veins (CMVs) are located along slip surfaces in the fault gouge zones. Some CMVs have a cataclastic fabric, and their branches intrude into voids around the slip surfaces. Raman spectra of the CMVs show a wide (full width at half maximum $>200 \mathrm{~cm}^{-1}$ ) D-peak at $\sim 1345 \mathrm{~cm}^{-1}$ (defect peak), which is much lower than the O-peak at $\sim 1595 \mathrm{~cm}^{-1}$ (ordered peak), indicating a metamorphic temperature of zeolite facies or lower than $250^{\circ} \mathrm{C}$. In addition, the stable carbon isotopic compositions $\left(\delta^{13} \mathrm{C}\right.$ values) of the CMVs, ranging from -23.4 to $-26.4 \%$, are very similar to that of the kerogen collected from the Late Triassic Xujiahe Formation in Sichuan Basin. Given the data at which it may be formed, the Xujiahe Formation is the most likely origin of CMs for the CMVs, and it seems that some CMVs in the fault zone were crushed and intruded into the voids during coseismic events, possibly driven by an enhanced pore fluid pressure. Since graphitization is suggested as an indicator of transient frictional heating in this area, our study providing a reference data set of CMs would help future CM-rich fault-zone research to retrieve seismic signatures presumably occurring in the Longmen Shan fault zone belt.
\end{abstract}

Keywords: Carbonaceous material vein, Origin, Formation, Wenchuan earthquake fault zone

\section{Background}

Tectonic veins in a fault zone always yield important information on the (1) stress, strain, pressure, temperature, fluid composition, and origin as well as on the (2) processes activated. For example, pseudotachylite is referred to as "fossil earthquakes" (Lin 2008), as it indicates a melting process induced by coseismic frictional heating (Sibson 1975). Additionally, ultracataclastic veins found in a seismic fault zone suggest crushing and the rapid injection of fluidized fine-grained materials associated with seismic faulting (Lin 2011).

Here, we report narrow veins of carbonaceous materials (CMs) present in the Longmen Shan fault belt that ruptured during the $2008 \mathrm{Mw} 7.9$ Wenchuan earthquake.

\footnotetext{
* Correspondence: lihaibing06@163.com

${ }^{2}$ Key Laboratory of Continental Tectonics and Dynamics, MLR, Institute of Geology, Chinese Academy of Geological Sciences, Beijing 100037, China Full list of author information is available at the end of the article
}

Since CM could be irreversibly graphitized owing to coseismic frictional heating, the graphite present in a fault zone could remarkably lower the strength of a fault (Oohashi et al. 2011; Kuo et al. 2014). Further, the inner organized order of $\mathrm{CM}$ is a potential thermometer for recording the seismic frictional heat anomaly (Hirono et al. 2009; Sakaguchi et al. 2011; Kitamura et al. 2012; Fulton and Harris 2012; Mori et al. 2015). Thus, CMVs are inferred to record information about the seismic faulting processes in the Longmen Shan fault belt.

This study aims to answer the questions of where the CMs in the CMVs originate and how the CMVs form. We observed the CMVs at outcrops, and in thin sections, examined the carbon isotope compositions of the CMVs and estimated the heating temperature conditions that the CMVs have experienced. These characterizations of the CMVs provide the necessary baseline for future studies of carbonaceous fault rock from the Longmen Shan fault belt

\section{Springer}


and permit comparison with drilled fault cores such as Wenchuan earthquake Fault Scientific Drilling (WFSD) projects.

\section{Geological setting}

The 2008 Wenchuan earthquake occurred along the Longmen Shan fault belt located at the junction of the eastern Tibet Plateau and the Sichuan Basin (Fig. 1a). It generated a $\sim 230$-km-long surface rupture zone along the central fault of the Longmen Shan fault belt, the Yingxiu-Beichuan fault (YBF) (Li et al. 2008; Xu et al. 2009; Liu-Zeng et al. 2010; Fu et al. 2011; Lin 2011),which has been active since the Late Cretaceous (Xu et al. 2008; Yan et al. 2011).

Our study area is located at Bajiaomiao village located on the southern segment of the Yingxiu-Beichuan coseismic surface rupture zone (Fig. 1a). At this outcrop, the SW-striking YBF has southeastwardly thrust

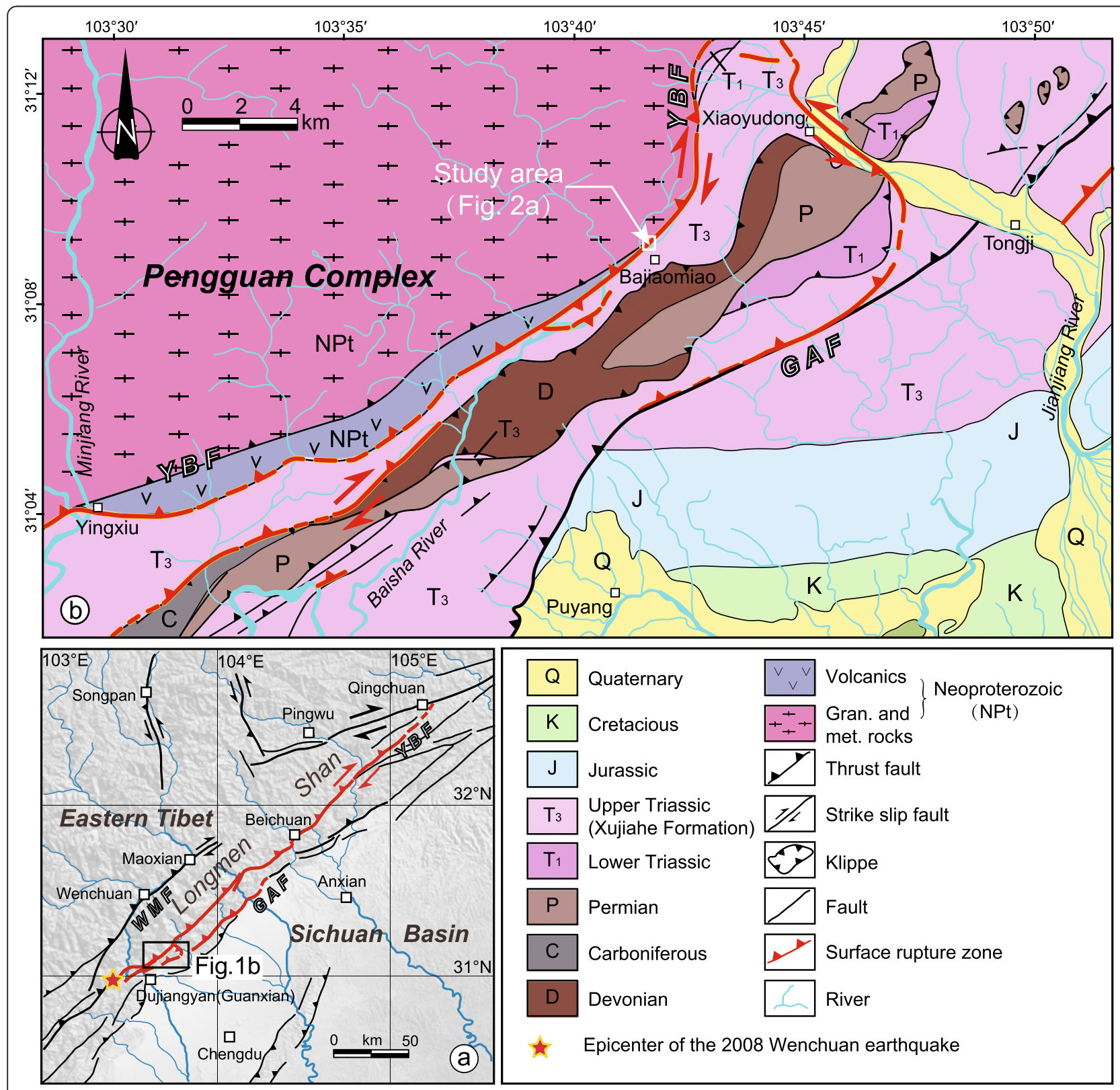

Fig. 1 Geological maps around the study area. a Coseismic surface rupture zones of the Wenchuan earthquake and geological structures of the Longmen Shan area and surroundings (modified from the 1:500,000 geologic map, Ministry of Geology and Mineral Resources 1991 and from the 1:200,000 geologic map of Guanxian, Sichuan Bureau of Geology 1975). The surface rupture zones of the Wenchuan earthquake are from Li et al. (2013). b Coseismic surface rupture zones of the Wenchuan earthquake and geological structures at the Bajiaomiao outcrop in (a). WMF-Wenchuan-Maowen fault, YBF-Yingxiu-Beichuan fault, GAF-Guanxian-Anxian fault 
the Pengguan complex over the Late Triassic Xujiahe Formation (Fig. 1b). The Pengguan complex consists of Neoproterozoic granitic rocks, volcanic rocks, and green schist metamorphic rocks, while the Upper Triassic Xujiahe Formation is composed of conglomerate, sandstone, and carbonaceous mudstone and coal seams.

Emplaced by a debris flow, a NS-trending 240-mlong profile perpendicular to the fault zone has cropped out at Bajiaomiao (Fig. 2a) and exposed the inner structures and fault rocks of the fault zone well. The fault zone consists of five fault rock units: cohesive gray cataclasite with pseudotachylite veins in the Pengguan complex, black fault gouge + breccia, gray fault breccia, dark-gray fault breccia, and black fault gouge + breccia in the Xujiahe Formation from north to south (Fig. 2) (Wang et al. 2014). The surface rupture zone of Wenchuan earthquake was located at the southern boundary of the fault zone and thrust fault rocks onto the alluvial deposits by a vertical displacement of $\sim 6 \mathrm{~m}$ ( $\mathrm{Li}$ et al. 2008; Xu et al. 2009; Liu-Zeng et al. 2010; Fu et al. 2011; Lin 2011) (Fig. 2).

\section{Methodology}

One trench was excavated across the fault zone (Fig. 2a), and fault rock samples containing CMVs were collected on the north wall of the trench (Fig. 2b, c). The typical CMVs in appearance are found in two fault gouges. One is just next to the surface rupture, and the other is about $4 \mathrm{~m}$ northwest of the surface rupture (Fig. 2b, c).

The fault rock samples were initially collected in large blocks with each edge more than $15 \mathrm{~cm}$. They were impregnated with epoxy before preparing standard petrographic thin sections in the direction parallel to the fault slip direction and perpendicular to the strike of the fault. Microstructures of the CMVs were optically analyzed using an Olympus BX51 optical microscope.

The degree of graphitization of the CMs is a useful tool to estimate the metamorphic temperature conditions. In particular, its indicating indexes such as the vitrinite reflectance thermometer (Sakaguchi et al. 2011; Fulton and Harris 2012; Kitamura et al. 2012) and the Raman spectra of CM thermometer (Hirono et al. 2009; Mori et al. 2015) record the frictional heat anomaly produced in a very seismic duration. To investigate the metamorphic temperature conditions and possible existing friction heat anomaly of the CMVs, laser Raman measurements were conducted onsite within thin sections. Raman spectra were obtained using a Renishaw RM1000 spectrometer equipped with a Peltier-cooled CCD detector. An ionized argon laser with a green ray at $514 \mathrm{~nm}$ and a $\times 50$ objective were used. The spatial resolution was $1 \mu \mathrm{m}$. The samples were measured over a spectral window of $1000-1800 \mathrm{~cm}^{-1}$ with a $1 \mathrm{~cm}^{-1}$ resolution. The experimental procedure uses a $25-\mathrm{mW}$ laser, which continuously decreases before reaching the section surface, and complete Raman spectra in the required region were acquired. The essential parameters for the peaks were defined using the computer program PeakFit (Systat Software Inc.)

An analysis of the stable carbon isotope composition of the CMVs helps to identify the origin of the CMs. Carefully selected samples from the collected fault rock samples were dried, grinded, and treated with a $1 \mathrm{M} \mathrm{HCl}$ solution for $24 \mathrm{~h}$ to remove carbonates. They were packed in tin cups and burned into $\mathrm{CO}_{2}$ before driven into the analyzer by a helium flow. The stable isotope ratio analyzer is a Finnigan MAT253 mass spectrometer. The results are reported as $\delta^{13} \mathrm{C}$ relative to the Peedee belemnite (PDB) limestone standard. The precision of $\delta^{13} \mathrm{C}$ was $\pm 0.1 \%$ based on a replicate analysis of the International Atomic Energy Agency (IAEA) standard. The standard material is IAEA-600, $\delta^{13} \mathrm{C}=-27.771 \pm 0.043 \%$.

\section{Results}

Structures

Black and shiny CMVs are very common on the walls of the trench, particularly in fault gouges (Fig. 2). Most of the CMVs parallel with each other extend along the fault planes (Fig. $2 b-d$ ), and they are often offset by subsidiary faults. Close observations show that an individual vein is usually $<2-\mathrm{cm}$ wide and up to 1 -m long (Figs. $2 \mathrm{~d}$ and 3 ). In thin sections, some of the CMVs have been offset into boudins parallel with oblique foliations (P-shear) defined by phyllosilicate minerals (muscovite and chlorite).

The CMVs almost completely consist of the CMs (Fig. 3). Localized discontinuous surfaces (faults, joints, and cracks) formed within the CMVs, but neither a distributed cataclasis process nor plastic deformation was observed in the veins (Fig. 3c). Additionally, no calcite, quartz, or other minerals deposited in association with the CMVs are observed (Fig. 3).

Some of the CMVs in the fault zone are characterized by distinctive cataclastic flow inner microstructures. These veins consist of $80 \mathrm{vol} \%$ randomly oriented angular CM fragments with 20 vol\% "hard" minerals (quartz, feldspar, calcite, and pyrite) and wall-rock fragments sitting in the CM matrix. The individual cataclastic flow accommodates the obvious displacements between its two boundaries. The hard minerals are arranged either in asymmetric lensoid aggregations indicating the shear sense of the displacement (Fig. 4a, b) or in chains parallel to the fault (Fig. $4 a-c$ ). However, neither foliation nor grain-scale plastic deformation is observed in the cataclastic flows. We also note that the branches of cataclastic flow intrude into the cracks around the flows and form a network of injection veins (Fig. $4 \mathrm{~d}-\mathrm{g}$ ). 


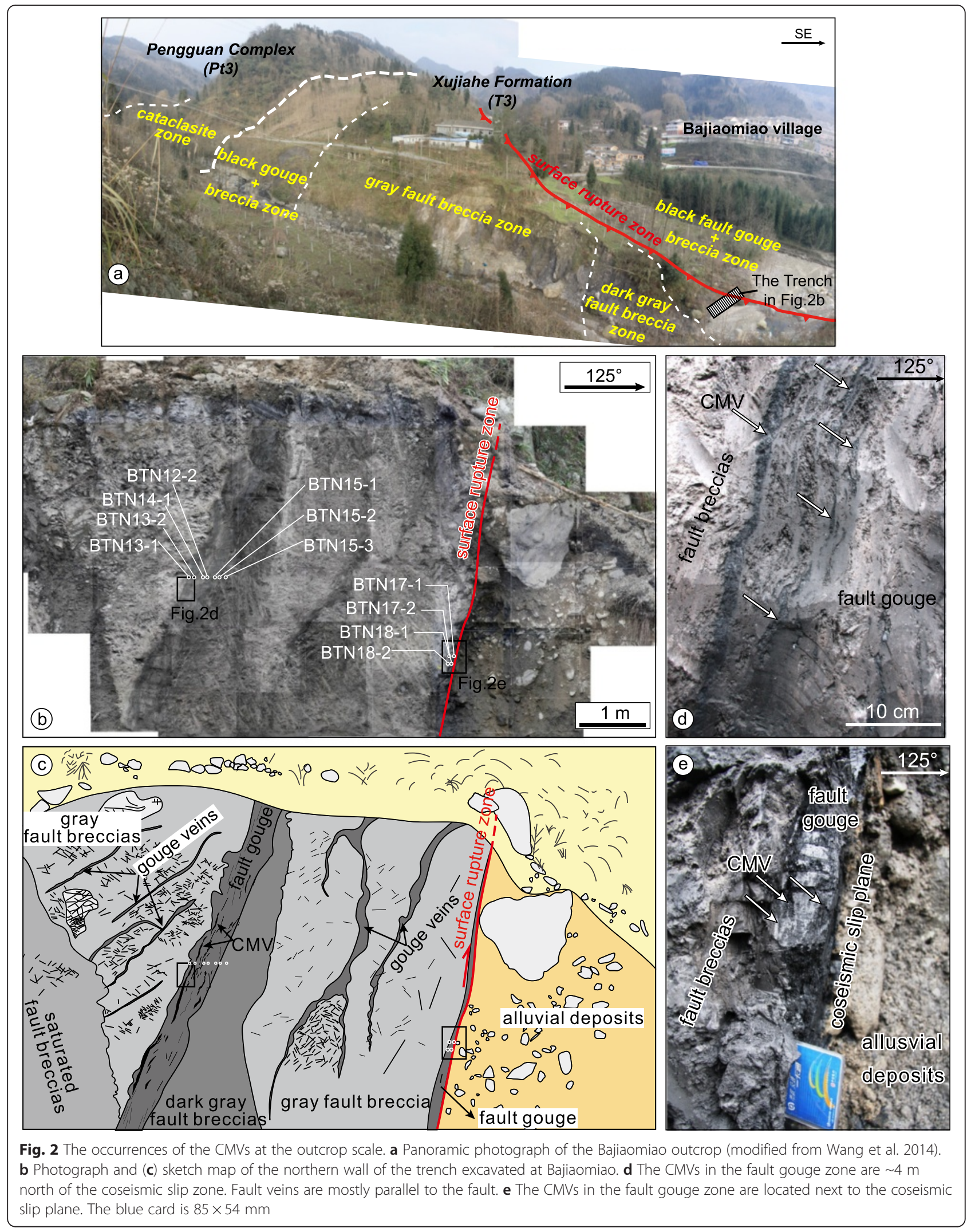



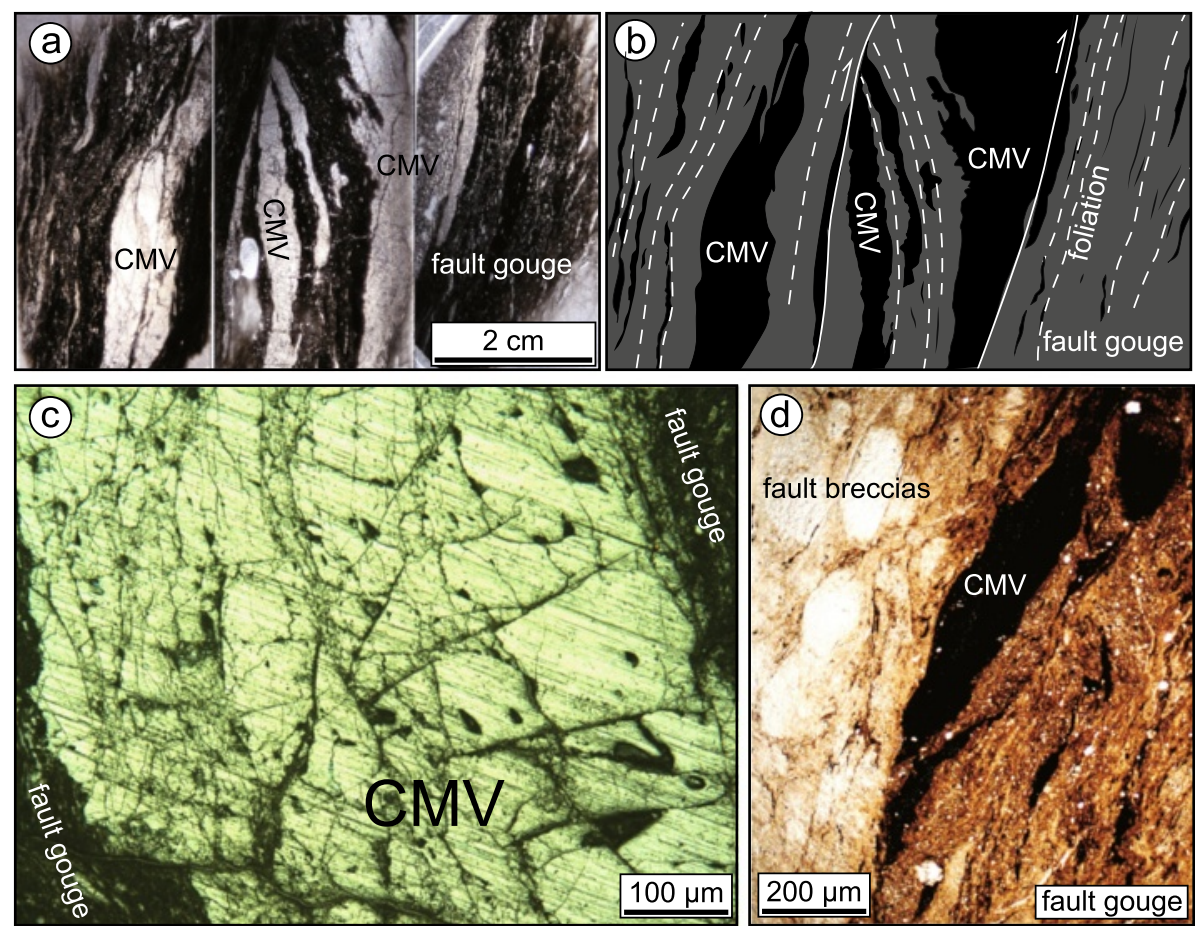

Fig. 3 Microstructures of the CMVs. a Photograph of the CMVs within thin sections. The highly reflective CMV is in white. b Sketch of (a). Dashed lines represent foliations. $\mathbf{c}$ Reflected-light photomicrograph of a CMV. $\mathbf{d}$ Plane-polarized-light photomicrograph of the CMV. $\mathbf{a}-\mathbf{c}$ Close-ups of the CMVs from Fig. 2d, and (d) is a magnification of Fig. $2 e$

\section{Characteristics of Raman spectra}

The Raman spectra of the CMVs exhibit similar features (Fig. 5). The spectra consist of two main peaks. One occurs at $\sim 1345 \mathrm{~cm}^{-1}$ (the "disordered" D-peak) and the other (the ordered O-peak) at $\sim 1595 \mathrm{~cm}^{-1}$. The O-peak might consist of a graphite peak (graphite or G-peak) and a disordered peak (D2-peak) but is very difficult to deconvolve. Another disordered peak (D4-peak) appears as a shoulder on the D peak $\left(1200 \mathrm{~cm}^{-1}\right.$, D4-peak).

As the D4-peak has not been counted in previously proposed geothermometers and the D2-peak cannot be reasonably deconvolved from the G-peak, we fit the spectra of the CMVs with D- and O-peaks by a Voigt function (Fig. 5). The spectra of the CMVs, including the ones with cataclastic flow structures, are separated into a lower wide D-peak and a higher O-peak. All parameters are quasi-constant and display no discernible trend. The width at the half maximum height for the D-peaks, $D_{\mathrm{W}}$, is about $250 \mathrm{~cm}^{-1}$. The ratio of peak intensities of the $\mathrm{D}$ - and the O-peaks $(\mathrm{D} / \mathrm{O})_{\mathrm{H}} \approx 0.5$.

\section{Stable carbon isotopes}

The $\delta^{13} \mathrm{C}$ values of the CMVs fall into a range from -23.4 to $-26.4 \%$ and do not show a clear trend with various distances from the fault planes (Table 1).

\section{Discussion}

Origin of CMs for the CMVs

The hanging wall of the YBF is composed of Neoproterozoic granitic (diorite and porphyrite) and volcanic rocks both in the field and on the cores from WFSD-1. The plenty amount of CMs in the fault zone should not originate from the hanging wall of the fault.

On the contrary, our results clearly demonstrated that the footwall of the fault is the most likely origin for the CMs. The wide D-peaks $\left(D_{\mathrm{w}} \approx 250 \mathrm{~cm}^{-1}\right)$ and D-peaks lower than the G-peaks in the Raman spectra of the CMVs are comparable to the features of the spectra of the CMs that have experienced a zeolite facies grade metamorphism (Yui et al. 1996) or a $<250{ }^{\circ} \mathrm{C}$ grade metamorphism (Rahl et al. 2005). This estimated temperature matches the burial depth of the Xujiahe Formation well, which is no more than $8 \mathrm{~km}$ in the western Sichuan Basin (Jia et al. 2010).

Melt pseudotachylite has been discovered in the YBF zone, reflecting a $1100-1700{ }^{\circ} \mathrm{C}$ frictional heating temperature achieved during earthquakes (Wang et al. 2015); this might be localized in the principle slip zone of the fault. We understand that the temperatures estimated by the Raman spectra reflect regional metamorphism temperatures with no or slight influences of frictional heating. Though Rahl et al. (2005) extended 

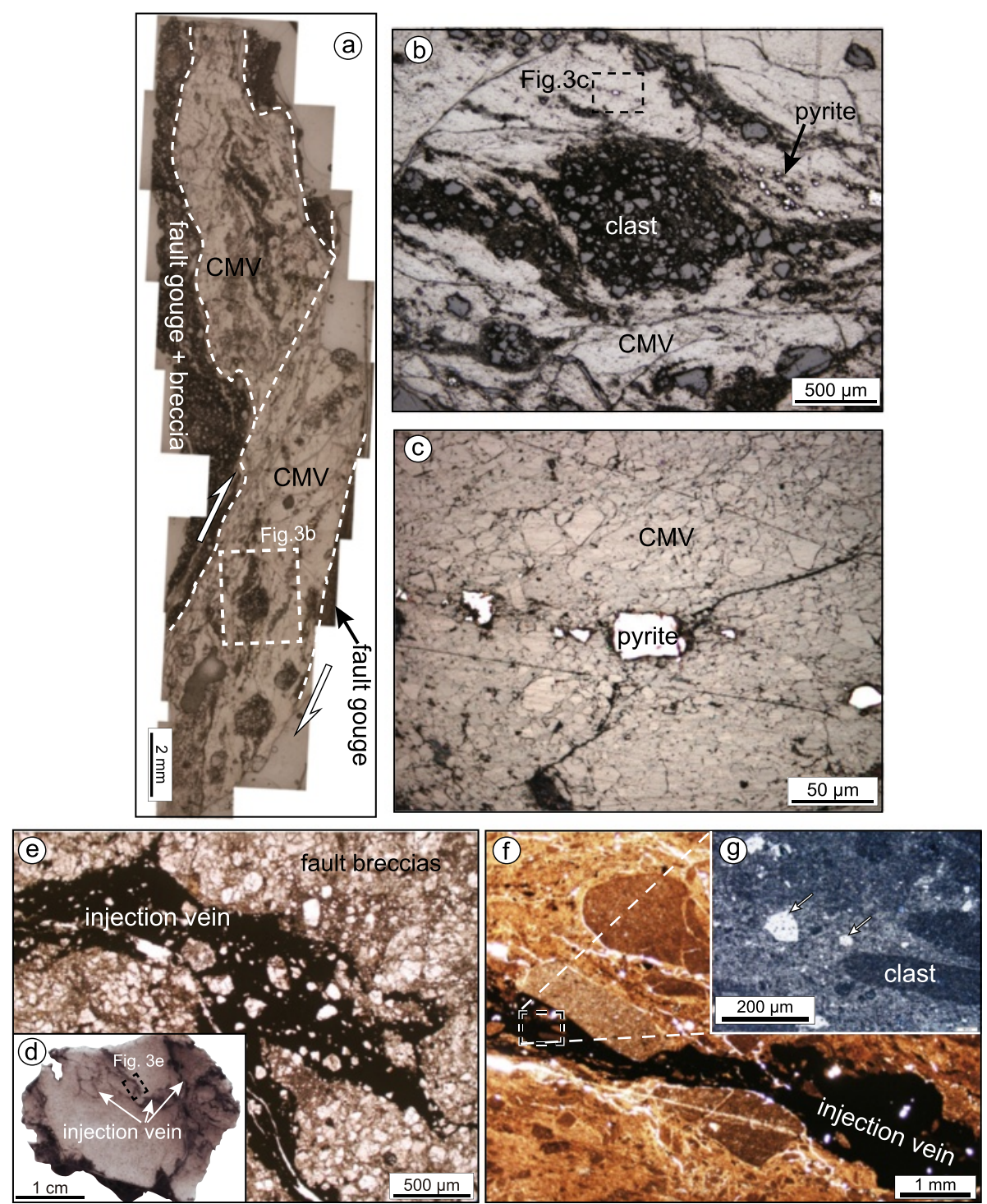

Fig. 4 Microstructures of the CMVs deformed by a cataclastic flow. a Movement of the fault accommodated by a cataclastic flow. $\mathbf{b}$ The lens-shaped clast in the cataclastic flow indicates the shear sense of the fault. Hard mineral grains (quartz, feldspar, and calcite) in gray (at the top) and pyrite (at the middle-right) occur in chains. c Chains of pyrite. Notice that no foliation forms and wraps the hard pyrite grains. The cataclastic flows intrude into void spaces in fault breccias $4 \mathrm{~m}$ west of the coseismic slip surface $(\mathbf{d}-\mathbf{e})$ and in a fault gouge along the coseismic slip surface $(\mathbf{f}-\mathbf{g})$. Figures $4 \mathbf{d}-\mathbf{f}$ is taken under plane-polarized light and the others under reflected light

the Raman spectra of a CM thermometer to temperatures as low as $100{ }^{\circ} \mathrm{C}$, the uncertainty range of the thermometer is still as large as $\pm 50{ }^{\circ} \mathrm{C}$. Since the estimated heating temperature of the CMVs is lower than $250{ }^{\circ} \mathrm{C}$ here, it is very difficult to estimate the seismic heating conditions from the Raman spectra of the CMVs.

The $\delta^{13} \mathrm{C}$ values of the CMVs ranging from -23.4 to $-26.4 \%$ fall well into the $\delta^{13} \mathrm{C}$ value range of the CMs in the Late Triassic Xujiahe Formation, about -24 to $-27 \%$ o (Dai et al., 2009). The later data are determined from type II and III kerogen collected from the dark mudstones of the
Xujiahe Formation in the northwest and central Sichuan Basin, which is a stable tectonic region (Dai et al. 2009).

The lithology of the WFSD-1 cores from 585.75 (the fault plane of the YBF) to $759-\mathrm{m}$ depth is mainly gray sandstone, dark-gray siltstone, carbon shale, and coal lines, corresponding to the third section of the Xujiahe Formation ( $\mathrm{Li}$ et al. 2013), while the total organic carbon (TOC) of the third section is up to $9.7 \%$ (Dai et al. 2009). In other words, the trench we studied is localized in the carbon-rich section of the Xujiahe Formation. Therefore, we conclude that the Xujiahe Formation is the most likely origin for the CMs in the CMVs. 


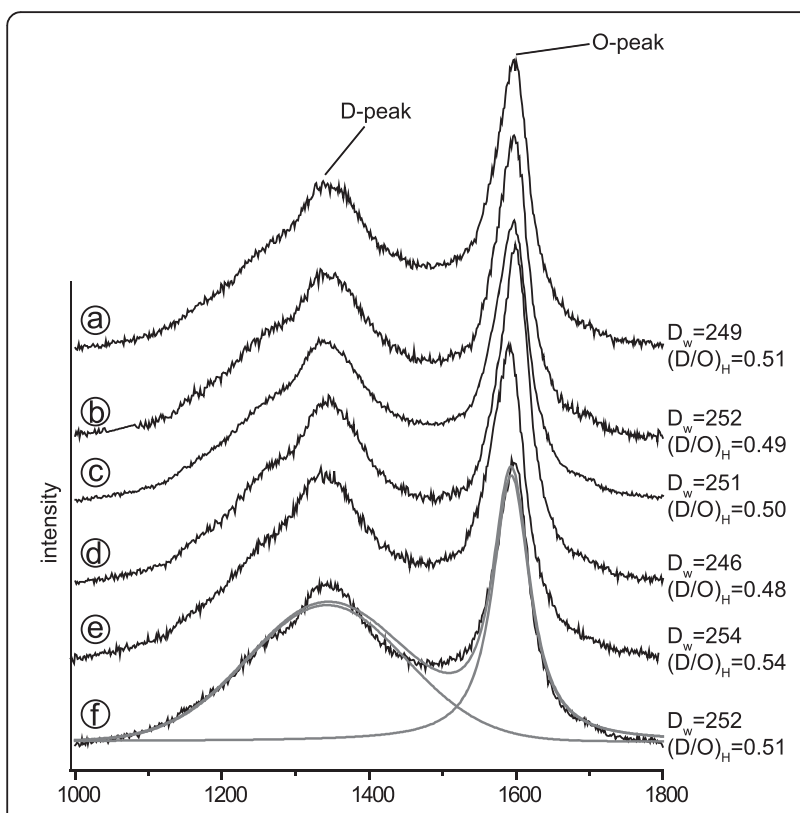

Fig. 5 Respective Raman spectra of the CMVs. a-b Spectra of CMVs from the fault gouge zone near the coseismic slip zone. c- $\mathbf{d}$ Spectra of CMVs from the fault gouge zone $\sim 4 \mathrm{~m}$ northwest of the coseismic slip zone. e-f Spectra of the cataclastic flow of the CMVs in Fig. $4 a$

We also consider other possible origins of CMs: (1) CMs are possibly deposited from $\mathrm{C}-\mathrm{O}-\mathrm{H}$ fluids migrating in along the fault zone by changes in the physical-chemical conditions (e.g., Khanchuk et al. 2013; Mathez et al. 1995; Pasteris and Chou. 1998), but we did not find other minerals deposited together with the CMs yet, and (2) the $\mathrm{CMs}$ might be the product of the chemical reaction $\mathrm{CO}_{2}+\mathrm{CH}_{4} \rightarrow 2 \mathrm{C}+2 \mathrm{H}_{2} \mathrm{O}$ due to coseismic frictional heating (Mathez et al. 2008), as $\mathrm{CH}_{4}$ and $\mathrm{CO}_{2}$ are the predominant components of gas emission measured along the YBF both before (Du et al. 2006) and after the Wenchuan earthquake (Zheng et al. 2013; Zhou

Table 1 Stable carbon isotope composition $\left(\delta^{13} \mathrm{C}\right)$ values of the CMVs

\begin{tabular}{lll}
\hline Sample number & Position (distances to the faults) & $\delta^{13} \mathrm{C}(\%)$ \\
\hline BTN13-1 & $42 \mathrm{~cm}$ to F1 & -25.1 \\
BTN13-2 & $36 \mathrm{~cm}$ to F1 & -24.2 \\
BTN14-1 & $20 \mathrm{~cm}$ to F1 & -23.7 \\
BTN14-2 & $13 \mathrm{~cm}$ to F1 & -24.6 \\
BTN15-1 & $7 \mathrm{~cm}$ to F1 & -24.1 \\
BTN15-2 & $-2 \mathrm{~cm}$ to F1 & -23.4 \\
BTN15-3 & $-14 \mathrm{~cm}$ to F1 & -25.0 \\
BTN17-1 & $19 \mathrm{~cm}$ to F2 & -25.7 \\
BTN17-2 & $23 \mathrm{~cm}$ to F2 & -26.4 \\
BTN18-1 & $22 \mathrm{~cm}$ to F2 & -24.0 \\
BTN18-2 & $27 \mathrm{~cm}$ to F2 & -26.1 \\
\hline
\end{tabular}

The southeast of the faults is the negative side for the sampled positions et al., 2010). However, the plentiful amount of CMs present in the veins seems to be in conflict with this idea. We are not sure whether the CMs from these origins exist in the fault zone. If so, the volume percent must be very low.

\section{Formation of the CMVs}

The CMVs present along slip surfaces (fault planes or foliations) in the fault zone suggest that the formation of the CMVs can be determined by the localized shear. However, the fact that the CMVs only record a low regional metamorphic temperature condition denies the possibility that the CMVs formed by a heat melting process. Meanwhile, the lack of minerals like calcite or quartz deposited with the CMs also contradicts the idea that the CMVs are deposited from fluids.

The Xujiahe Formation in the footwall of the YBF is the most likely origin of the CMs for the CMVs. Compared with other types of rocks in the sand-shale sequence of the Xujiahe Formation, the carbonaceous layers such as coal seams express a much lower compressive strength when the fault zone is subject to a regional stress. The weak carbonaceous layers would easily intrude into the fault zone and smear along the fault plane during either seismic or aseismic faulting. As introduced above, the composition and inner structure of the CMVs match this formation mechanism well. Though no source layers of the CMVs are observed at the outcrop, we should emphasize that the smears of weak layers in the sand-shale sequence can be as long as $100 \mathrm{~m}$ (Egholm et al. 2008). The source layers of the CMVs may be either destroyed or actually outside of the outcrop.

The branches of the CMVs with a cataclastic fabric intrude into cracks around the CMVs. However, this plastic deformation progressed via brittle deformation (sliding and rotation) at the grain scale. Instead of foliation or plastic deformation, asymmetric lensoid aggregations and chains of 'hard' minerals in the cataclastic flow indicate that these CMVs formed during faulting. However, the microstructures of these CMVs are totally different from those of the mylonite and fault gouges. An obvious comminution and grain-size reduction process in the cataclastic CMVs means that the structures of these veins have been changed by very rapid faulting events, maybe intense earthquakes. If this is the case, frictional heat would enhance the temperature of the pore fluids which induce their thermal expansion; thus, the fine-grain materials become fluidized and intrude into the cracks around the cataclastic CMVs.

What is worth noting is that extra pore pressure may exist in the CMVs. The CMs such as coals have a very high porosity; in particular, the sheared coals possess three to eight times more porosity and two to ten times more specific surface area than normal coals (Li and Ogawa. 2001). 
The high content of $\mathrm{CH}_{4}$ and $\mathrm{CO}_{2}$ stored in the CMVs would be instantaneously released when the CMVs were disturbed by a seismic event.

In conclusion, the CMVs in the YBF zone are smears of the CM layers of the Xujiahe Formation. A few of the CMV in the fault zone were crushed and intruded into the voids during seismic events.

\section{Conclusions}

We identify that the Late Triassic Xujiahe Formation is the most likely the origin for the CMs of the CMVs in the Wenchuan earthquake fault zone based on the microstructures, the heating condition reflected by the Raman spectra, and $\delta^{13} \mathrm{C}$ values of the CMVs. The CMVs are actually smears of the carbonaceous layers of the Xujiahe Formation, and some of them were crushed and intruded into the voids during earthquakes.

This paper establishes a reference CM data set from the active fault zone of the Longmen Shan fault that ruptured in the 2008 Mw7.9 Wenchuan earthquake and presents an application their study to both other exhumed carbonaceous-rich fault zones and deep drilling cores.

\section{Abbreviations}

CM: carbonaceous material; CMV: carbonaceous material vein;

GAF: Guanxian-Anxian fault; WMF: Wenchuan-Maowen fault; YBF: YingxiuBeichuan fault.

\section{Competing interests}

The authors declare that they have no competing interests.

\section{Authors' contributions}

$J L, H L, J Z$, and BZ carried out most of the field work. $J L$ and BZ finished the analysis of the microstructures. JL finished the Raman spectrum analysis. $J L$ and HL conceived and coordinated the study and drafted the manuscript. All authors have read and approved the final manuscript.

\section{Acknowledgements}

We thank Yang Wang, Congyuan Yin, and Meng Wang of the EBSD laboratory of Peking University for their help with SEM imaging and thank Marie-Luce Chevalier for improving the English writing in this paper. This research was supported by the National Natural Science Foundation of China (NSFC grants 41402181, 41330211, and 41302169).

\section{Author details}

'Xi'an Center of Geological Survey, CGS, Key Laboratory of the Study of Focused Magmatism and Giant Ore Deposits, MLR, Xi'an 710054, China. ${ }^{2}$ Key Laboratory of Continental Tectonics and Dynamics, MLR, Institute of Geology, Chinese Academy of Geological Sciences, Beijing 100037, China. ${ }^{3}$ Key Laboratory of Orogenic Belts and Crustal Evolution, Ministry of Education, School of Earth and Space Sciences, Peking University, Beijing 100871, China.

Received: 1 April 2015 Accepted: 4 February 2016

Published online: 11 February 2016

\section{References}

Dai JX, Ni YY, Zou CN, Tao SZ, Hu GY, Hu AP, Yang C, Tao XW (2009) Stable carbon isotopes of alkane gases from the Xujiahe coal measures and implication for gas-source correlation in the Sichuan Basin, SW China. Org Geochem 40:638-646

Du JG, Cheng WZ, Zhang YL, Jie CL, Guan ZJ (2006) Helium and carbon isotopic compositions of thermal springs in the earthquake zone of Sichuan, Southwestern China. J Asian Earth Sci 26:533-539

Egholm DL, Clausen OR, Sandiford M, Kristensen MB, Korstgard JA (2008) The mechanics of clay smearing along faults. Geology 36(10):787-790
Fu BH, Shi PL, Guo HD, Okuyama S, Ninomiya Y, Wright S (2011) Surface deformation related to the 2008 Wenchuan earthquake, and mountain building of the Longmen Shan, eastern Tibetan Plateau. J Asian Earth Sci 40(4):805-824

Fulton PM, Harris RN (2012) Thermal considerations in inferring frictional heating from vitrinite reflectance and implications for shallow coseismic slip within the Nankai Subduction Zone. Earth Planet Sci Lett 335-336:206-215

Hirono T, Ujiie K, Ishikawa T, Mishima T, Hamada Y, Tanimizu M, Wonn S, Kinoshita M (2009) Estimation of temperature rise in a shallow slip zone of the megasplay fault in the Nankai Trough. Tectonophysics 478:215-220

Jia D, Li YQ, Lin AM, Wang MM, Chen W, Wu XJ, Ren ZK (2010) Structural model of $2008 M_{w} 7.9$ Wenchuan earthquake in the rejuvenated Longmen Shan thrust belt, China. Tectonophysics 491:174-184

Khanchuk Al, Plyusnina LP, Ruslan AV, Likhoidov GG, Barinov NN (2013) Nature of graphitization and noble metal mineralization in metamorphic rocks of the northern Khanka terrane, Primorye. Geol Ore Deposit, 55(4):225-244.

Kitamura M, Mukouyoushi H, Fulton PM, Takehiro H (2012) Coal maturation by frictional heating during rapid fault slip. Geophys Res Lett 39:16302. doi:10. 1029/2012GL052316

Kuo LW, Li HB, Smith SAF, Di Toro G, Suppe J, Song SR, Nielsen S, Sheu HS, Si JL (2014) Gouge graphitization and dynamic fault weakening during the 2008 Mw 7.9 Wenchuan earthquake. Geology 42(1):47-50

Li HB, Fu XF, van der Word J, Si JL, Wang ZX, Hou LW, Qiu ZL, Li N, Wu FY, Xu ZQ, Tapponnier P (2008) Co-seisimic surface rupture and dextral-slip oblique thrusting of the Ms 8.0 Wenchuan earthquake. Acta Geol Sin 82(12):1623-1643 (in Chinese with English abstract)

Li HB, Wang H, XU ZQ, Si JL, Pei JL, Li TF, Huang Y, Song SR, Kuo LW, Sun ZM, Chevalier ML, Liu DL (2013) Characteristics of the fault-related rocks, fault zones and the principal slip zone in the Wenchuan Earthquake Fault Scientific Drilling Project Hole-1 (WFSD-1). Tectonophysics 584:23-42

Li HY, Ogawa Y (2001) Pore structure of sheared coals and related coalbed methane. Environ Geol 40:1455-1461

Lin AM (2008) Fossil earthquakes: The formation and preservation of pseudotachylytes. Springer-Verlag, Heidelberg, Berlin, p 348

Lin AM (2011) Seismic slip recorded by fluidized ultracataclastic veins formed in a coseismic shear zone during the $2008 \mathrm{Mw} 7.9$ Wenchuan earthquake. Geology 39(6):547-550

Liu-Zeng J, Wen L, Sun J, Zhang ZH, Hu GY, Xing XC, Zeng LS, Xu Q (2010) Surficial slip and rupture geometry on the Beichuan Fault near Hongkou during the Mw 7.9 Wenchuan Earthquake, China. Bull Seismol Soc Am 100(5B):2615-2650

Mathez EA, Duba AG, Peach CL, Lé ger A, Shankland TJ (1995) Electrical conductivity and carbon in metamorphic rocks of the Yukon-Tanana Terrane, Alaska. J Geophys Res 100(87):10187-10196

Mathez EA, Roberts JJ, Duba AG, Kronenberg AK, Karner SL (2008) Carbon deposition during brittle rock deformation: Changes in electrical properties of fault zones and potential geoelectric pheonomena during earthquakes. J Geophys Res 113:B12201

Mori H, Walls S, Fujimoto K, Shigematsu N (2015) Recognition of shear heating on a long-lived major fault using Raman carbonaceous material thermometry: implications for strength and displacement history of the MTL, SW Japan. Island Arc 24:425-446

Oohashi K, Hirose T, Shimamoto T (2011) Shear-induced graphitization of carbonaceous materials during seismic fault motion: experiments and possible implications for fault mechanics. J Struct Geol 33:1122-1134

Pasteris JD and Chou IM (1998) Fluid-deposited graphitic inclusions in quartz: Comparison between KTB (German continental Deep-Drilling) core samples and artificially reequilibrated natural inclusions. Geochim Cosmochim Acta 62(1):109-122

Rahl JM, Anderson KM, Brandon MT, Fassoulas C (2005) Raman spectroscopic carbonaceous material thermometry of low-grade metamorphic rocks: calibration and application to tectonic exhumation in Crete, Greece. Earth Planet Sci Lett 240:339-354

Sakaguchi A, Chester F, Curewitz D, Fabbri O, Goldsby D, Kimura G, Li CF, Masaki Y, Screaton EJ, Tsutsumi A, Ujiie K, Yamaguchi A (2011) Seismic slip propagation to the updip end of plate boundary subduction interface faults: vitrinite reflectance geothermometry on Integrated Ocean Drilling Program NanTro SEIZE cores. Geology 39(4):395-398

Sibson RH (1975) Generation of pseudotachylyte by ancient seismic faulting. The Geophysical Journal of the Royal Astronomical Society 43(3):775-794

Wang H, Li HB, Janssen C, Sun ZM, Si JL (2015) Multiple generations of pseudotachylyte in the Wenchuan fault zone and their implications for coseismic weakening. J Struct Geol 74:159-171 
Wang H, Li HB, Si JL, Sun ZM, Huang Y (2014) Internal structure of the Wenchuan earthquake fault zone, revealed by surface outcrop and WFSD-1 drilling core investigation. Tectonophysics 619-620:101-114

Xu XW, Wen XZ, Yu GH, Chen GH, Klinger Y, Hubbard J, Shaw JH (2009)

Coseismic reverse- and oblique-slip surface faulting generated by the 2008 Mw 7.9 Wenchuan earthquake, China. Geology 37(6):515-518

Xu ZQ, Ji SC, Li HB, Hou LW, Fu XF, Cai ZF (2008) Uplift of the Longmen Shan range and the Wenchuan earthquake. Episodes 31:91-301

Yan DP, Zhou MF, Li SB, Wei GQ (2011) Structural and geochronological constraints on the Mesozoic-Cenozoic tectonic evolution of the Longmen Shan thrust belt, eastern Tibetan Plateau. Tectonics 30, TC6005. doi:10.1029/ $2011 \mathrm{TC} 002867$

Yui TF, Huang E, Xu J (1996) Raman spectrum of carbonaceous material: a possible metamorphic grade indicator for low grade metamorphic rocks. J Metamorph Geol 14:115-124

Zheng GD, Xu S, Liang SY, Shi PL, Zhao J (2013) Gas emission from the Qingzhu River after the 2008 Wenchuan earthquake, Southwest China. Chem Geol 339:187-193

Zhou XC, Du JG, Chen Z, Cheng JW, Tang Y, Yang LM, Xie C, Cui YJ, Liu L, Yi L, Yang PX, Li Y (2010) Geochemistry of soil gas in the seismic fault zone produced by the Wenchuan Ms 8.0 earthquake, southwestern China. Geochem Trans 11:5

\section{Submit your manuscript to a SpringerOpen ${ }^{\odot}$ journal and benefit from:}

- Convenient online submission

- Rigorous peer review

- Immediate publication on acceptance

- Open access: articles freely available online

- High visibility within the field

- Retaining the copyright to your article

Submit your next manuscript at $\boldsymbol{s p r i n g e r o p e n . c o m ~}$ 